OPEN ACCESS

Edited by:

Aleksandra Barac,

University of Belgrade, Serbia

Reviewed by:

Jose Roberto Lapa E. Silva,

Federal University of Rio de

Janeiro, Brazil

Ana Afonso,

University of São Paulo, Brazil

${ }^{*}$ Correspondence:

Lijin Zou

zou.li.jin@hotmail.com

Kaisen Chen

chenks100@126.com

Specialty section:

This article was submitted to Infectious Diseases - Surveillance,

Prevention and Treatment,

a section of the journal

Frontiers in Public Health

Received: 26 February 2019

Accepted: 17 June 2019

Published: 19 July 2019

Citation:

Chen $Q$, Peng L, Xiong G, Peng $Y$

Luo D, Zou L and Chen K (2019) Recurrence Is a Noticeable Cause of Rifampicin-Resistant Mycobacterium tuberculosis in the Elderly Population in Jiangxi, China.

Front. Public Health 7:182.

doi: 10.3389/fpubh.2019.00182

\section{Recurrence Is a Noticeable Cause of Rifampicin-Resistant Mycobacterium tuberculosis in the Elderly Population in Jiangxi, China}

\author{
Qiang Chen ${ }^{1}$, Linfeng Peng ${ }^{2}$, Guangchu Xiong ${ }^{3}$, Yiping Peng ${ }^{3}$, Dong Luo ${ }^{1}$, Lijin Zou ${ }^{4 *}$ and \\ Kaisen Chen ${ }^{1 *}$ \\ ${ }^{1}$ Department of Clinical Laboratory, The First Affiliated Hospital of Nanchang University, Nanchang, China, ${ }^{2}$ Department of \\ Respiratory, The First Affiliated Hospital of Nanchang University, Nanchang, China, ${ }^{3}$ Department of Clinical Laboratory, \\ Jiangxi Chest Hospital, Nanchang, China, ${ }^{4}$ Department of Burns, The First Affiliated Hospital of Nanchang University, \\ Nanchang, China
}

Setting: Rifampicin-resistant tuberculosis (RR-TB) in elderly people in Jiangxi Province, China.

Objective: To investigate the incidence of RR-TB and risk factors in elderly people within a hospital setting in China.

Design: Retrospective cohort study.

Methods: A comparative study was performed to analyze RR-TB and rifampicin-susceptible TB (RS-TB). The 15-locus mycobacterial interspersed repetitive unit-variable number of tandem repeats (MIRU-VNTR) method was used to distinguish between relapse and reinfection.

Results: Twenty-three recurrent cases occurred in 151 elderly patients with RR-TB, and 24 recurrent cases occurred in 466 elderly patients with RS-TB during this period. TB recurrence was significantly different in the RR-TB and RS-TB groups (OR $=0.35,95 \%$ Cl: 0.14-0.88; $\left.\chi^{2}=5.28, P=0.03\right)$. Comparing the risk factors for RR-TB and RS-TB, we found that educational level, age, and pulmonary cavity were inextricably linked to RR-TB in elderly patients. Furthermore, pulmonary cavity, HIV status, and alcohol consumption were associated with recurrence in elderly RR-TB patients.

Conclusions: Recurrence is an important source of RR-TB in the elderly population. It is necessary to promptly treat tuberculosis patients, prevent the spread of AIDS, and reduce alcohol intake to control recurrent RR-TB in the elderly population.

Keywords: tuberculosis, recurrence, rifampicin-resistant, elderly patients, China

\section{INTRODUCTION}

Tuberculosis (TB) has remained a serious public health concern in China and is one of the top 10 causes of death and the leading cause of death due to a single infectious agent. The World Health Organization (WHO) estimated that there were 10.0 million new cases of TB, including 0.56 million rifampicin-resistant TB (RR-TB) cases, in 2017, and of these, $82 \%$ were multidrug-resistant TB 
(MDR-TB) (1). Owing to the low success of treatment and longer treatment period, RR-TB patients bear greater spiritual and financial burdens, especially elderly patients who have significantly reduced physical function, owing to comorbidities such as diabetes, hypertension, and rheumatism $(2,3)$. Identifying the cause of RR-TB is important for its accurate and timely management.

In 2017, China became the country with the largest elderly population in the world, with 240.9 million people aged 60 years and above, accounting for $17.3 \%$ of the total population according to the data from the Chinese National Bureau of Statistics. It is manifest that there are many underlying diseases and increasing poverty in the elderly population due to their disability and decreasing ability to perform labor as well as the partial deficiency of the social security system. As a result, some geriatric TB patients have become a growing social problem (4, 5). The underdeveloped economic level and problems associated with an aging population mean that the rapidly increasing incidence of TB in Jiangxi Province is not an optimistic situation (6). It is urgent to know the epidemiological characteristics and infectious patterns in elderly TB patients to support better TB control and prevention.

To determine the prevalence of TB in the elderly population and the characteristics of these elderly patients, especially elderly RR-TB patients, we collected clinical and sociodemographic information from January 2008 to December 2016 in Jiangxi Chest Hospital. Through a comparative study, we identified some risk factors for RR-TB, and we also found that recurrence was a significant factor responsible for RR-TB in the elderly population.

\section{STUDY POPULATION AND METHODS Study Population and Mycobacterium tuberculosis Isolates}

This retrospective study was performed at the Jiangxi Chest Hospital from January 1, 2008, to December 31, 2016, and all data were obtained from the hospital information database. The Jiangxi Chest Hospital is located in Nanchang, an important city in southeast China. Approximately 12,000 patients with pulmonary $\mathrm{TB}$ are treated in this hospital every year, coming from all parts of Jiangxi Province. Pulmonary TB patients were recruited during this period. Three sputa samples at different time points (spot, early, and night) from each patient who was suspected of having pulmonary TB were collected for acidfast bacilli (AFB) testing using the Ziehl Neelsen (ZN) method and Löwenstein-Jensen culturing. Thiophene carboxylic acid hydrazide $(\mathrm{TCH})$ and $p$-nitrobenzoic acid (PNB) were used to differentiate between $M$. tuberculosis complex (MTBC) and nontuberculosis mycobacteria (NTM). The study was approved by the ethics committee of the First Affiliated Hospital of Nanchang University, Nanchang, China (approval number: 2014036). At the same time, this study was also approved by the Jiangxi Chest Hospital Institutional Review Board (IRB). All personal data were kept confidential. Written informed consent was obtained from each participant prior to the study. We confirmed that all adopted methods were conducted in accordance with the relevant guidelines and regulations in China.

\section{Drug Susceptibility Testing}

For all M. tuberculosis isolates collected, drug susceptibility testing (DST) was routinely performed using BACTEC MGIT 960 (BD) to measure susceptibility to eight types of anti-TB drugs according to the MGIT 960 operating manual (7). These drugs included isoniazid (INH) $(0.2 \mu \mathrm{g} / \mathrm{ml})$, rifampin (RIF) $(40.0 \mu \mathrm{g} / \mathrm{ml})$, streptomycin (SM) $(4.0 \mu \mathrm{g} / \mathrm{ml})$, ethambutol (EMB) $(2.0 \mu \mathrm{g} / \mathrm{ml})$, ofloxacin (OFL) $(1.0 \mu \mathrm{g} / \mathrm{ml})$, kanamycin (KAN) $(30.0 \mu \mathrm{g} / \mathrm{ml})$, amikacin (AMK) $(40.0 \mu \mathrm{g} / \mathrm{ml})$, and capreomycin (CMP) $(40.0 \mu \mathrm{g} / \mathrm{ml})$. Quality control was routinely performed using the reference strain $\mathrm{H} 37 \mathrm{Rv}$ (ATCC27294). The results were interpreted according to the relevant published literature (8).

\section{Data Collection and Definitions}

During the study period, all information on 3,264 pulmonary TB culture-positive patients at the Jiangxi Chest hospital was obtained. The patients' data were collected, including sex, age, marital status, history of diabetes, TB treatment history, educational levels, presence of pulmonary cavities, HIV status, smoking habits, sputum smear results, and place of residence. The term "elderly TB patients" refers to patients who were no $<60$ years old, and the term "young TB patients" refers to patients who were $<60$ years old and more than 18 years old when they were diagnosed with TB at the first episode. Recurrent patents in this study met the criteria previously reported in the literature (9). Essentially, there are two aspects to the criteria for recurrence: (1) completion of the standard anti-TB treatment process and (2) more than two episodes of diagnosed TB (within a minimum time interval of 12 months based on the date of the end of treatment for the first episode). Non-recurrent TB cases are defined as TB patients who test positive for the first time. Relapse, known as endogenous reactivation, is caused by the same strain that caused the first episode of TB. Alcohol consumption refers to the daily consumption of more than $10 \mathrm{~g}$ of alcohol, and heavy alcohol consumption refers to a daily consumption of more than $40 \mathrm{~g}$ of alcohol. The place of residence refers to the place where the household registration is located, which is usually divided into rural residences and urban residences.

\section{DNA Extraction and Sequencing}

Bacterial genomic DNA was obtained from the isolates by the boiled lysis method. All RIF-resistant strains (MTB isolates from the first episode) were included in this study. A 442-bp oligonucleotide fragment of the $r p o B$ gene was amplified and sequenced (including an 81-bp core RIF resistance determining region) [454-FLX Sequencer (Roche), Sangon Bio Co., Shanghai, China]. The primer sequences and PCR conditions were based on previously reported studies $(10,11)$. The primers were synthesized by Sangon Bio Co., (Shanghai, China). The PCR mixtures were prepared using $2 \times$ Taq MasterMix (Tiangen Co., Beijing, China). Sequencing data were assembled and analyzed with Mega5.04 software.

\section{Genotyping Method}

Fifteen-locus MIRU-VNTR amplification was performed to genotype the recurrent RIF-resistant strains following the protocol described in our previous report (12). In brief, all MIRU-VNTRs were amplified by normal PCR, and then the 
PCR products were separated by electrophoresis on $1.5 \%$ agarose gels, and the size analysis of the PCR fragments was performed with the Gel Image Analysis System (LiuYi Co., Beijing, China). The numbers of repetitions of various MIRU-VNTR loci were determined by comparison with the reference strain H37Rv. A reinfection case was defined by the occurrence of strains with different MIRU-VNTR patterns between the first and second TB episodes; a relapse case was defined by the occurrence of strains with the same MIRU-VNTR patterns (9).

\section{Statistical Analysis}

Chi-square tests or Fisher's exact tests were used to compare the proportions of patients in each subgroup (such as RR-TB or RSTB patients; recurrent or non-recurrent TB patients). Odds ratios (ORs) and 95\% confidence intervals (95\% CIs) were calculated in the univariate analyses. All statistical procedures were performed with SPSS version 17.0 software (SPSS Inc., Chicago, IL, USA). Values of $P<0.05$ were considered statistically significant.

\section{RESULTS}

\section{Recurrence Is an Important Risk Factor for Elderly RR-TB Patients}

In total, 3,264 pulmonary TB patients visited the Jiangxi Chest Hospital during the indicated period, and $18.90 \%(617 / 3,264)$ of those patients were elderly people. Among them, $24.47 \%$ (151/617) had RR-TB, including 23 with recurrent TB and 128 with non-recurrent TB (Figure 1). Among the 23 patients with recurrent TB, 3 died, 19 had one recurrence, and 1 had two or more recurrent episodes during this study period. Furthermore, $75.53 \%(466 / 617)$ of the patients had RIF-susceptible TB, including 24 with recurrent $\mathrm{TB}$ and 442 with non-recurrent TB. The results showed that the recurrent status played a more important role in elderly RR-TB patients than in elderly RS-TB patients $(\mathrm{OR}=0.35,95 \% \mathrm{CI}: 0.14-0.88 ; P=0.03)$.

\section{Clinical Characteristics of Elderly RR-TB Patients}

When examining the clinical characteristics of elderly RRTB patients, we primarily compared them with those of RIFsusceptible elderly patients. The results indicated that educational level, age, and the presence of pulmonary cavities were important risk factors in elderly RR-TB patients. However, factors such as sex, HIV status, alcohol consumption, smear positivity, place of residence, and career had no influence on the appearance of RIFresistant or RIF-susceptible TB (Table 1). To further understand the characteristics of elderly RR-TB patients, we also compared different clinical and social demographic characteristics between patients with recurrent and non-recurrent TB. Overall, there was a significantly higher proportion of patients with recurrent TB among the HIV-positive patients, indicating that HIV status was an important risk factor for $\mathrm{TB}$ recurrence $(\mathrm{OR}=5.80,95 \%$ CI: $2.13-15.79 ; P=0.01)$. Furthermore, alcohol consumption and the presence of pulmonary cavities also played vital roles in recurrence $(\mathrm{OR}=0.28,95 \% \mathrm{CI}: 0.11-0.71 ; P=0.02)$, particularly in rural men. In contrast, educational level, age, sex, a history of

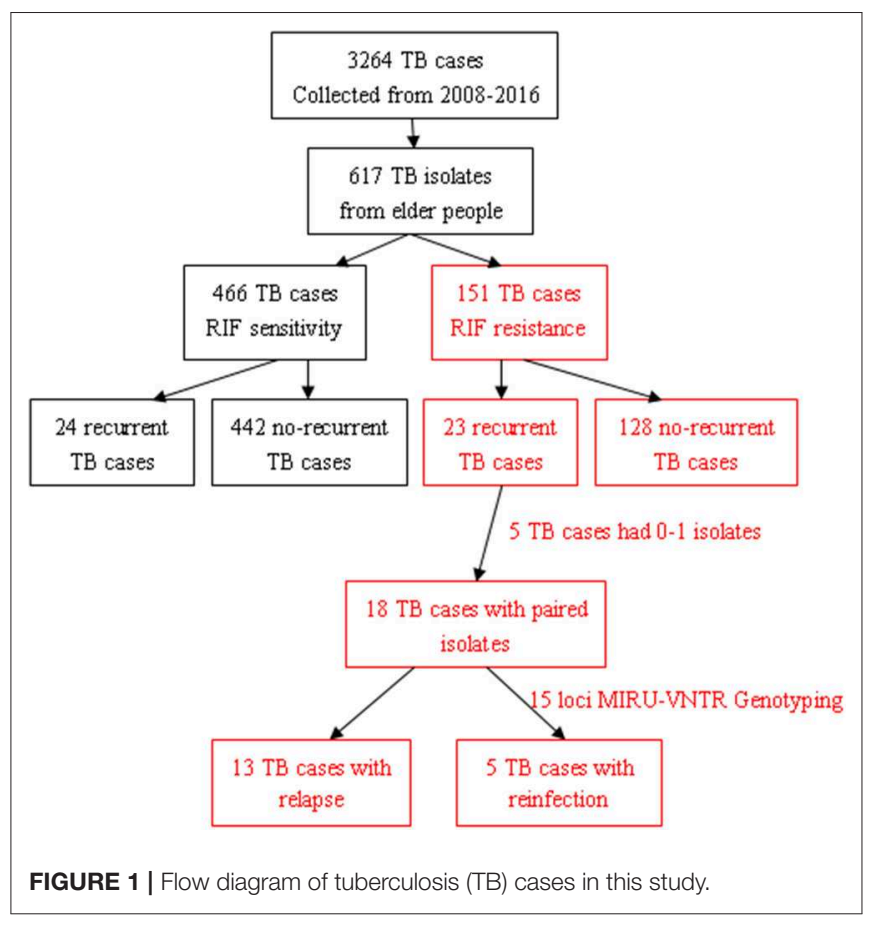

diabetes, smear positivity, and place of residence had no influence on the percentage of patients who relapsed (Table 2).

\section{Molecular Characteristics of RR-TB Strains in Elderly Patients}

Except for 8 wild-type strains, the remaining RIF-resistant strains harbored mutations within the 81-bp RIF resistance determining region (RRDR). Altogether, 94.7\% (143/151) of the RR-TB isolates harbored mutations in 10 residues in RRDR. The most frequently mutated rpoB was Ser531 (91/151, $60.3 \%$ ), with 87 Ser531Leu and 4 Ser531Phe, of which 15 appeared in patients with recurrent $\mathrm{TB}$ and 76 appeared in patients with non-recurrent TB. The second most frequently mutated point was residue His526, with 4 His526Asp, 13 His526Pro, and 4 His526Leu. All five double mutants showed mutations in the core region RRDR. There was no significant difference between patients with recurrent and non-recurrent TB $(P>0.05)$ (Table 3).

\section{Drug-Resistance Profiles in RR-TB Strains in Elderly Patients}

In total, 151 RR-TB strains were included in our study. Some strains carried other drug-resistant patterns. For example, in all 23 patients with recurrent TB, 11 strains were resistant to SM, 20 were resistant to INH, 6 were resistant to EMB, 3 were resistant to $\mathrm{KAN}, 8$ were resistant to CMP, 5 were resistant to AMK, and 3 were resistant to OFL. Correspondingly, in all 128 patients with non-recurrent TB, 49 strains were resistant to SM, 109 were resistant to $\mathrm{INH}, 11$ were resistant to EMB, 18 were resistant to KAN, 44 were resistant to $\mathrm{CMP}, 16$ were resistant to $\mathrm{AMK}$, and 20 were resistant to OFL (Figure 2). However, there 
TABLE 1 | Demographic and clinical characteristics of RIF-resistant and RIF-susceptible elderly TB cases in this study.

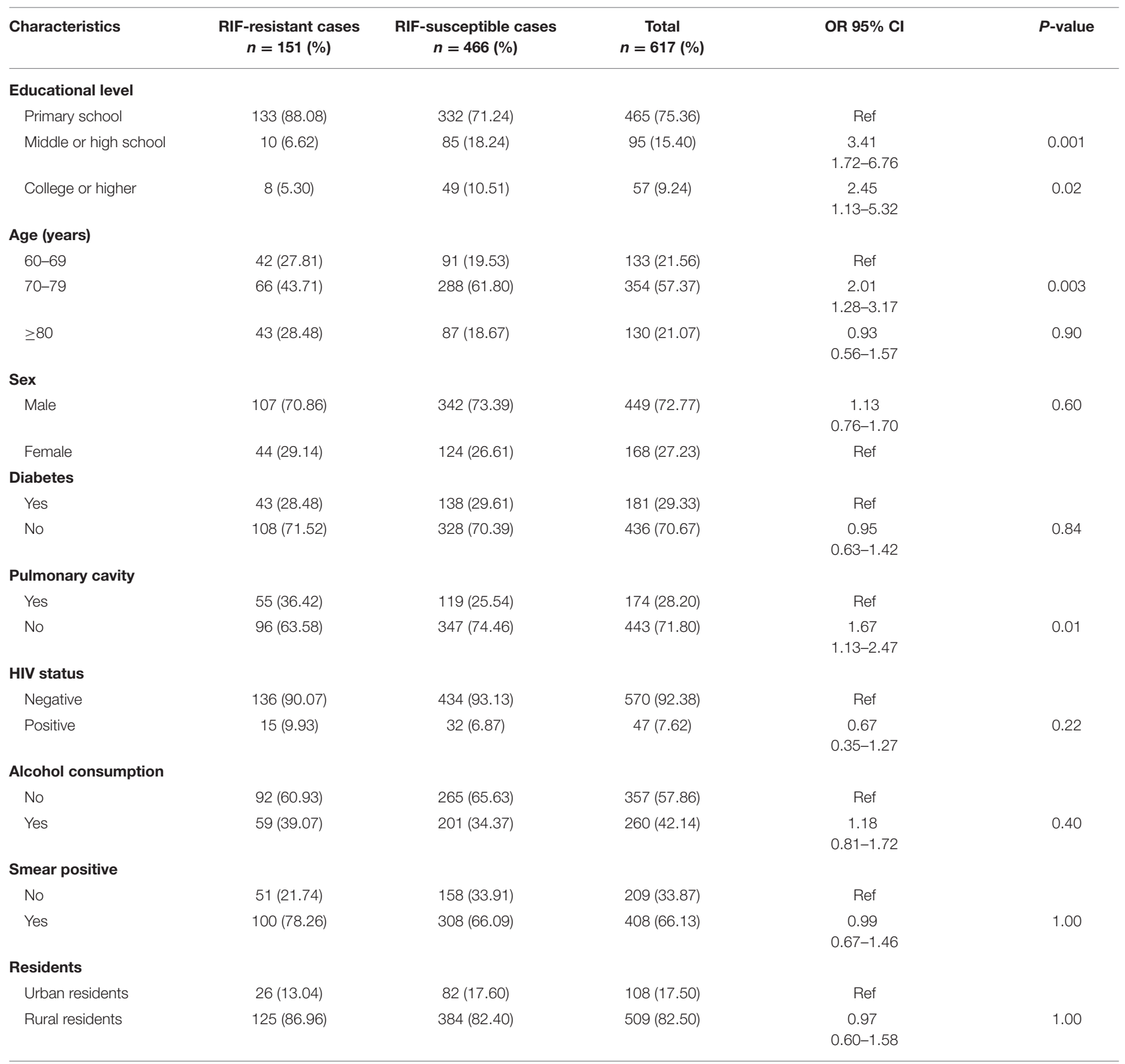

was no significant difference between patients with recurrent and non-recurrent TB $(P>0.05)$.

\section{Relapse Was More Common in Elderly RR-TB Patients}

During this study period, 16 of 23 patients with recurrent TB acquired second strains, and the MIRU-VNTR results showed that 13 had identical genotypes and 3 acquired different genotypes. As a result, we considered that relapse was the major reason $(13 / 16,81.25 \%)$ for recurrence in those patients. When comparing the effects of different factors on relapse or reinfection, we found no statistically significant differences based on gender, age, educational level, HIV status, alcohol consumption, smear positivity, the presence of pulmonary cavities, or career (data not shown).

\section{DISCUSSION}

To better understand the situation of elderly TB patients in Jiangxi Province, we performed a detailed investigation of culture-confirmed patients from January 1, 2008, to December 31,2016 , in a tertiary TB care hospital. We found 617 elderly 
TABLE 2 | Demographic and clinical characteristics of RIF-resistant elderly TB cases in this study.

\begin{tabular}{|c|c|c|c|c|c|}
\hline Characteristics & $\begin{array}{c}\text { Recurrent } \\
\text { cases } n=23(\%)\end{array}$ & $\begin{array}{c}\text { Non-recurrent } \\
\text { cases } \\
n=128(\%)\end{array}$ & $\begin{array}{c}\text { Total } \\
n=151(\%)\end{array}$ & $\begin{array}{c}\text { OR } \\
95 \% \mathrm{Cl}\end{array}$ & $\begin{array}{c}P \\
\text {-value }\end{array}$ \\
\hline \multicolumn{6}{|l|}{ Educational level } \\
\hline Primary school & 18 (78.26) & 115 (89.84) & 133 (88.08) & Ref & \\
\hline Middle or high school & $3(13.04)$ & $7(5.47)$ & $10(6.62)$ & $\begin{array}{c}0.37 \\
0.09-1.54\end{array}$ & 0.16 \\
\hline College or higher & $2(8.70)$ & $6(4.69)$ & $8(5.30)$ & $\begin{array}{c}0.47 \\
0.09-2.51\end{array}$ & 0.32 \\
\hline \multicolumn{6}{|l|}{ Age (years) } \\
\hline $60-69$ & $8(34.78)$ & $34(26.56)$ & $42(27.81)$ & $\begin{array}{c}0.85 \\
0.31-2.33\end{array}$ & 0.80 \\
\hline $70-79$ & $11(47.83)$ & 55 (42.97) & 66 (43.71) & Ref & \\
\hline$\geq 80$ & $4(17.39)$ & $39(30.47)$ & $43(28.48)$ & $\begin{array}{c}1.95 \\
0.58-6.58\end{array}$ & 0.40 \\
\hline \multicolumn{6}{|l|}{ Sex } \\
\hline Female & $6(26.09)$ & 38 (29.69) & $44(29.14)$ & Ref & \\
\hline Male & 17 (73.91) & 90 (70.31) & $107(70.86)$ & $\begin{array}{c}0.84 \\
0.31-2.28\end{array}$ & 0.81 \\
\hline \multicolumn{6}{|l|}{ Diabetes } \\
\hline Yes & $12(52.17)$ & 46 (35.94) & $58(38.41)$ & Ref & \\
\hline No & $11(47.83)$ & 82 (64.06) & 93 (61.59) & $\begin{array}{c}1.95 \\
0.80-4.76\end{array}$ & 0.17 \\
\hline \multicolumn{6}{|l|}{ Pulmonary cavity } \\
\hline Yes & $17(73.91)$ & $42(32.81)$ & $59(39.07)$ & Ref & \\
\hline No & $6(26.09)$ & $86(67.19)$ & 92 (60.93) & $\begin{array}{c}5.80 \\
2.13-15.79\end{array}$ & 0.001 \\
\hline \multicolumn{6}{|l|}{ HIV status } \\
\hline Negative & $17(72.91)$ & $119(92.97)$ & $136(90.07)$ & Ref & \\
\hline Positive & $6(26.09)$ & $9(7.03)$ & $15(9.93)$ & $\begin{array}{c}4.67 \\
1.48-14.76\end{array}$ & 0.01 \\
\hline \multicolumn{6}{|l|}{ Alcohol consumption } \\
\hline No & $8(34.78)$ & 84 (65.63) & 92 (60.93) & Ref & \\
\hline Yes & $15(65.22)$ & $44(34.37)$ & $59(39.07)$ & $\begin{array}{c}0.28 \\
0.11-0.71\end{array}$ & 0.02 \\
\hline \multicolumn{6}{|l|}{ Smear positive } \\
\hline No & $5(21.74)$ & $46(35.94)$ & $51(33.77)$ & Ref & \\
\hline Yes & 18 (78.26) & 82 (64.06) & $100(66.23)$ & $\begin{array}{c}0.50 \\
0.17-1.42\end{array}$ & 0.24 \\
\hline \multicolumn{6}{|l|}{ Residents } \\
\hline Urban residents & $3(13.04)$ & $23(17.97)$ & $26(17.22)$ & Ref & \\
\hline Rural residents & $20(86.96)$ & 105 (82.03) & 125 (82.78) & $\begin{array}{c}0.69 \\
0.19-2.50\end{array}$ & 0.77 \\
\hline
\end{tabular}

TB patients among the overall 3,264 patients, which showed that elderly people still constitute a large proportion of the patients with TB (13). According to the local demographic data, the proportions of elderly with TB were relatively high in all age groups, which was consistent with the results of previous studies $(1,14)$. Furthermore, we found 151 RR-TB patients among the 617 elderly TB patients, and the isolation ratio was relatively high. Considering that most RR-TB patients have $\operatorname{MDR}-\mathrm{TB}(14,15)$, the incidence of MDR-TB appears to be very high among elderly people in Jiangxi Province (5). According to The International
Union Against Tuberculosis and Lung Disease, RR-TB should be treated similarly to MDR-TB (16).

To determine the mutation characteristics of the $r p o B$ gene among these recurrent RR-TB strains, we sequenced the RRDR of the $r p o B$ gene. We found that RIF resistance occurred primarily in the RRDR region of the $r p o B$ gene, consistent with the findings of a previous report (17). We also compared it with TB strains isolated from patients with non-recurrent $\mathrm{TB}$, and the results indicated that there were no obvious differences, which was consistent with some reports in the literature $(18,19)$. 
TABLE 3 | Distribution of mutations in rpoB gene among 151 RIF-resistant MTB from elderly patients in this study.

\begin{tabular}{|c|c|c|c|c|}
\hline \multirow[t]{2}{*}{ Locus } & \multicolumn{2}{|c|}{ Change } & \multicolumn{2}{|c|}{ No. $(\%)$ of isolates } \\
\hline & Nucleotide & Amino acid & $\begin{array}{l}\text { No. }(\%) \text { of } \\
\text { recurrent cases } \\
(n=23)\end{array}$ & $\begin{array}{c}\text { No. }(\%) \text { of } \\
\text { non-recurrent cases } \\
(n=128)\end{array}$ \\
\hline \multirow[t]{2}{*}{ rpoB531 } & $\mathrm{TCG} \rightarrow \pi \mathrm{TG}$ & Ser $\rightarrow$ Leu & $14(60.87)$ & $73(57.03)$ \\
\hline & $\mathrm{TCG} \rightarrow \pi \mathrm{T}$ & Ser $\rightarrow$ Phe & $1(4.35)$ & $3(2.34)$ \\
\hline \multirow[t]{3}{*}{ rpoB526 } & $\mathrm{CAC} \rightarrow \mathrm{GAC}$ & $\mathrm{His} \rightarrow \mathrm{Asp}$ & $1(4.35)$ & 3 (2.34) \\
\hline & $\mathrm{CAC} \rightarrow \mathrm{CCC}$ & $\mathrm{His} \rightarrow \mathrm{PrO}$ & $1(4.35)$ & $12(9.38)$ \\
\hline & $\mathrm{CAC} \rightarrow \mathrm{CTC}$ & His $\rightarrow$ Leu & $1(4.35)$ & 3 (2.34) \\
\hline rpoB516 & $\mathrm{GAC} \rightarrow \mathrm{GTC}$ & $\mathrm{Asp} \rightarrow \mathrm{Val}$ & $1(4.35)$ & $6(4.69)$ \\
\hline rpoB516/511 & $\begin{array}{l}\mathrm{GAC} \rightarrow \mathrm{GGC} \\
\mathrm{CTG} \rightarrow \mathrm{CCG}\end{array}$ & $\begin{array}{l}\text { Asp } \rightarrow \text { Gly } \\
\text { Leu } \rightarrow \text { Pro }\end{array}$ & $0(0.00)$ & $2(1.56)$ \\
\hline rpoB533 & $\mathrm{CTG} \rightarrow \mathrm{CCG}$ & Leu $\rightarrow$ Pro & $2(8.70)$ & $4(3.12)$ \\
\hline rpoB533/518 & $\begin{array}{l}\mathrm{CTG} \rightarrow \mathrm{CCG} \\
\mathrm{ATG} \rightarrow \mathrm{GTG}\end{array}$ & $\begin{array}{l}\text { Leu } \rightarrow \text { Pro } \\
\text { Met } \rightarrow \text { Val }\end{array}$ & $0(0.00)$ & $3(2.34)$ \\
\hline rpoB513 & $\mathrm{CAA} \rightarrow \mathrm{AA}$ & Gln $\rightarrow$ Lys & $1(4.35)$ & $8(6.25)$ \\
\hline rpoB519 & $\mathrm{AAC} \rightarrow \mathrm{AAG}$ & Asn $\rightarrow$ Lys & $0(0.00)$ & $1(0.01)$ \\
\hline Wild type & None & None & $1(4.35)$ & $7(5.47)$ \\
\hline
\end{tabular}

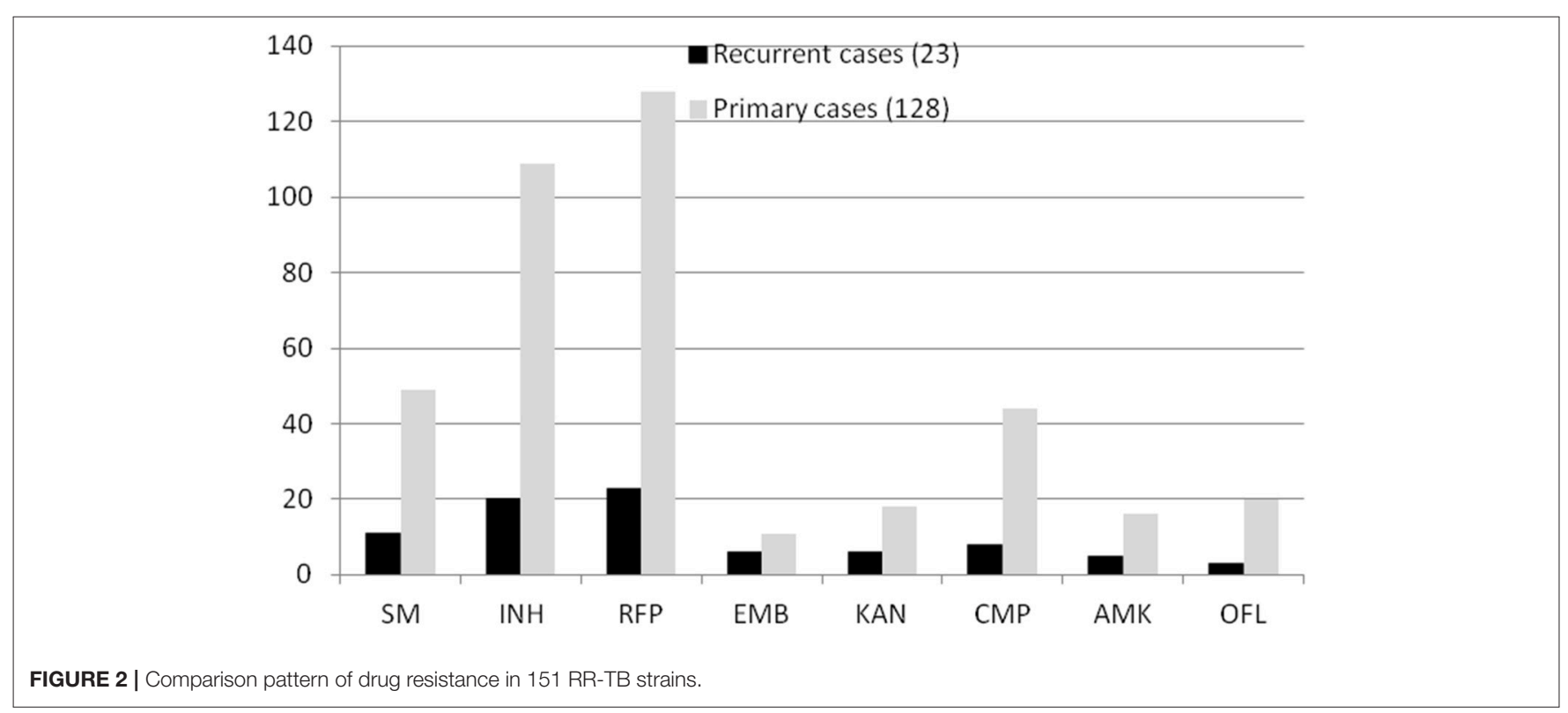

To prioritize the strategies for RR-TB control in the elderly population, it is necessary to know the risk factors associated with RR-TB in elderly patients. We compared RR-TB patients with RS-TB patients, and the results indicated that people with higher educational levels were less likely to acquire RR-TB. Compared with RS-TB, RR-TB was more likely to originate from recurrence and treatment failure (20-23); people with higher educational levels are more likely to have a highly structured life, making it easier to adhere accurately to a drug regimen $(24,25)$. The presence of pulmonary cavities was another risk factor; RR$\mathrm{TB}$ is an independent predictor of acquiring MDR-TB, and the presence of pulmonary cavities is an independent risk factor for MDR-TB (26).
Recurrence was a significant source of RR-TB among elderly patients $(P<0.05)$, so we sought to determine the risk factors for recurrence by comparing patients with recurrent $\mathrm{TB}$ with those with non-recurrent TB. Recurrence usually occurs if there is universal incorrect usage of rifamycin to treat primary $\mathrm{TB}$, according to the WHO guidelines (14). Furthermore, HIV positivity also had an important effect on RR-TB recurrence in this study; while that result was similar to the finding reported by Unis et al. (27), Guerra-Assuncǎo et al. (28) found that HIV positivity primarily affected reinfection rather than relapse. Our MIRU-VNTR data showed that 50\% (3/6) of HIV-positive patients with recurrent TB had been reinfected, and $50 \%$ had experienced relapse, which is inconsistent with 
results reported in the literature $(28,29)$. The reason may be the small sample size. Alcohol consumption was another risk factor, especially long-term heavy drinking in male patients (data not shown). Patients who engage in long-term heavy drinking usually live less regularly scheduled lives and do not adhere to the anti-TB drug regimen as required; furthermore, longterm drinking also impairs immune function (30). A long-term multiregional study has also confirmed a positive correlation between alcohol consumption and TB (31). Although some studies (32-34) found that diabetes had an important effect on TB occurrence, our study focused on elderly RR-TB patients; as a result, there was no significant difference between those with and without diabetes.

Our report had several limitations. First, the collected information was incomplete. The collection of TB patients did not originate from all TB units in the province but rather from the only comprehensive tertiary hospital; as a result, the information pertaining to some patients was not acquired if they did not visit the same hospital the next time. Furthermore, patients were not enrolled if they were only suspected of having relapse but did not have evidence of the same strain twice, which led to the underestimation of relapse. Furthermore, the interpretation of relapse and reinfection in elderly RR-TB patients should be considered with caution due to the limited number of specimens from patients with recurrent TB. However, because the Jiangxi Province Chest Hospital is the only tertiary TB hospital in Jiangxi Province, almost all patients with refractory disease, treatment failure, and recurrent TB seek care in this hospital; as a result, the study results have a high degree of credibility.

\section{REFERENCES}

1. World Health Organization. Global Tuberculosis Report. (2018). Available online at: https://www.aidsdatahub.org/global-tuberculosis-report-2018who- 2018

2. Htet KKK, Soe KT, Kumar AMV, Saw S, Win Maung HM, Myint Z, et al. Rifampicin-resistant tuberculosis patients in Myanmar in 2016: how many are lost on the path to treatment? Int J Tuberc Lung Dis. (2018) 22:385-92. doi: 10.5588/ijtld.17.0452

3. Júnior JCL, Ramos RTT, Robazzi TCMV. Treatment of latent tuberculosis in patients with juvenile rheumatic diseases: a systematic review. Rev Bras Reumatol Engl Ed. (2017) 57:245-53. doi: 10.1016/j.rbre.2017.01.009

4. Ngwira LG, Dowdy DW, Khundi M, Barnes GL, Nkhoma A, Choko AT, et al. Delay in seeking care for tuberculosis symptoms among adults newly diagnosed with HIV in rural Malawi. Int J Tuberc Lung Dis. (2018) 22:280-6. doi: 10.5588/ijtld.17.0539

5. Qi Z, Yang W, Wang YF. Epidemiological analysis of pulmonary tuberculosis in Heilongjiang province China from 2008 to 2015. Int J Mycobacteriol. (2017) 6:264-7. doi: 10.4103/ijmy.ijmy_104_17

6. Yuan X, Zhang T, Kawakami K, Zhu J, Zheng W, Li H, et al. Genotyping and clinical characteristics of multidrug and extensively drug-resistant tuberculosis in a tertiary care tuberculosis hospital in China. BMC Infect Dis. (2013) 13:315. doi: 10.1186/1471-2334-13-315

7. Iseman MD, Heifets LB. Rapid detection of tuberculosis and drug-resistant tuberculosis. N Engl J Med. (2006) 355:1606-8. doi: 10.1056/NEJMe068173

8. Ma AJ, Wang SF, Fan JL, Zhao B, He GX, Zhao YL. Genetic diversity and drug susceptibility of Mycobacterium tuberculosis isolates in a remote mountain area of China. Biomed Environ Sci. (2018) 31:351-62. doi: $10.3967 /$ bes2018.046

\section{CONCLUSION}

Our study demonstrated that recurrence is a very important factor for RR-TB in elderly patients in Jiangxi Province. It is necessary to administer more stringent standardized treatment to and conduct regular TB examinations in those patients.

\section{DATA AVAILABILITY}

The raw data supporting the conclusions of this manuscript will be made available by the authors, without undue reservation, to any qualified researcher.

\section{AUTHOR CONTRIBUTIONS}

All authors listed have made a substantial, direct and intellectual contribution to the work, and approved it for publication.

\section{FUNDING}

This study was supported by the National Natural Science Foundation of China (grant: 81660555) and Jiangxi Natural Science Foundation (grant: 2017BAB205074).

\section{ACKNOWLEDGMENTS}

The authors would like to thank all the patients who contributed their specimens and clinical data to this study. We were also very grateful to the microbiologists and technicians of Clinical Laboratory of the Jiangxi Chest Hospital for providing timely data for this manuscript.

9. Zong Z, Huo F, Shi J, Jing W, Ma Y, Liang Q, et al. Relapse versus reinfection of recurrent tuberculosis patients in a national tuberculosis specialized hospital in Beijing, China. Front Microbiol. (2018) 9:1858. doi: $10.3389 /$ fmicb. 2018.01858

10. Afanas'ev MV, Ikryannikova LN, Il'ina EN, Sidorenko SV, Kuz'min AV, Larionova EE, et al. Molecular characteristics of rifampicin- and isoniazidresistant Mycobacterium tuberculosis isolates from the Russian Federation. J Antimicrob Chemother. (2007) 59:1057-64. doi: 10.1093/jac/dkm086

11. Caws M, Duy PM, Tho DQ, Lan NT, Hoa DV, Farrar J. Mutations prevalent among rifampin- and isoniazid-resistant Mycobacterium tuberculosis isolates from a hospital in Vietnam. J Clin Microbiol. (2006) 44:2333-7. doi: 10.1128/JCM.00330-06

12. Chen KS, Liu T, Lin RR, Peng YP, Xiong GC. Tuberculosis transmission and risk factors in a Chinese antimony mining community. Int J Tuberc Lung Dis. (2016) 20:57-62. doi: 10.5588/ijtld.15.0215

13. Zhang Z, Lu J, Liu M, Wang Y, Qu G, Li H, et al. Genotyping and molecular characteristics of multidrug-resistant Mycobacterium tuberculosis isolates from China. J Infect. (2015) 70:335-45. doi: 10.1016/j.jinf.2014.11.008

14. He XC, Zhang XX, Zhao JN, Liu Y, Yu CB, Yang GR, et al. Epidemiological trends of drug-resistant tuberculosis in China from 2007 to 2014. Medicine. (2016) 95:e3336. doi: 10.1097/MD.0000000000003336

15. Zhao Y, Xu S, Wang L, Chin DP, Wang S, Jiang G, et al. National survey of drug-resistant tuberculosis in China. N Engl J Med. (2012) 366:2161-70. doi: 10.1056/NEJMoa1108789

16. Caminero JA. Guidelines for the Clinical and Operational Management of Drug-Resistant Tuberculosis and Lung Disease. (2013). Available online at: http://www.theunion.org/what-wedo/publications/technical/guidelinesfor-theclinical-and-operationalmanagement-of-drug-resistant-tuberculosis (accessed May 12, 2015). 
17. Almeida Da Silva PE, Palomino JC. Molecular basis and mechanisms of drug resistance in Mycobacterium tuberculosis: classical and new drugs. $J$ Antimicrob Chemother. (2011) 66:1417-30. doi: 10.1093/jac/dkr173

18. Poudel A, Nakajima C, Fukushima Y, Suzuki H, Pandey BD, Maharjan B, et al. Molecular characterization of multidrug-resistant Mycobacterium tuberculosis isolated in Nepal. Antimicrob Agents Chemother. (2012) 56:28316. doi: 10.1128/AAC.06418-11

19. Luo T, Zhao M, Li X, Xu P, Gui X, Pickerill S, et al. Selection of mutations to detect multidrug-resistant Mycobacterium tuberculosis strains in Shanghai, China. Antimicrob Agents Chemother. (2010) 54:1075-81. doi: 10.1128/AAC.00964-09

20. Ahmad Khan F, Gelmanova IY, Franke MF, Atwood S, Zemlyanaya NA, Unakova IA, et al. Aggressive regimens reduce risk of recurrence after successful treatment of MDR-TB. Clin Infect Dis. (2016) 63:214-20. doi: 10.1093/cid/ciw276

21. Alene KA, Yi H, Viney K, McBryde ES, Yang K, Bai L, et al. Treatment outcomes of patients with multidrug-resistant and extensively drug resistant tuberculosis in Hunan Province, China. BMC Infect Dis. (2017) 17:573. doi: 10.1186/s12879-017-2662-8

22. Sun Y, Harley D, Vally $H$, Sleigh A. Impact of multidrug resistance on tuberculosis recurrence and long-term outcome in China. PLoS ONE. (2017) 12:e0168865. doi: 10.1371/journal.pone.0168865

23. Umubyeyi AN, Shamputa IC, Rigouts L, Dediste A, Karita E, Struelens MJ, et al. Molecular investigation of recurrent tuberculosis in patients from Rwanda. Int J Tuberc Lung Dis. (2007) 11:860-7.

24. Miandad M, Nawaz-Ul-Huda S, Burke F, Hamza S, Azam M. Educational status and awareness among tuberculosis patients of Karachi. J Pak Med Assoc. (2016) 66:265-9.

25. Yap P, Tan KHX, Lim WY, Barkham T, Tan LWL, Chen MI, et al. Prevalence of and risk factors associated with latent tuberculosis in Singapore: a cross-sectional survey. Int J Infect Dis. (2018) 72:55-62. doi: 10.1016/j.ijid.2018.05.004

26. Roh HF, Kim J, Nam SH, Kim JM. Pulmonary resection for patients with multidrug-resistant tuberculosis based on survival outcomes: a systematic review and meta-analysis. Eur J Cardiothorac Surg. (2017) 52:673-8. doi: 10.1093/ejcts/ezx209

27. Unis G, Ribeiro AW, Esteves LS, Spies FS, Picon PD, Dalla Costa ER, et al. Tuberculosis recurrence in a high incidence setting for HIV and tuberculosis in Brazil. BMC Infect Dis. (2014) 14:548. doi: 10.1186/s12879-0140548-6
28. Guerra-Assunção JA, Houben RM, Crampin AC, Mzembe T, Mallard K, Coll F, et al. Recurrence due to relapse or reinfection with Mycobacterium tuberculosis: a whole-genome sequencing approach in a large, populationbased cohort with a high HIV infection prevalence and active follow-up. $J$ Infect Dis. (2015) 211:1154-63. doi: 10.1093/infdis/jiu574

29. Narayanan S, Swaminathan S, Supply P, Shanmugam S, Narendran G, Hari L, et al. Impact of HIV infection on the recurrence of tuberculosis in South India. J Infect Dis. (2010) 201:691. doi: 10.1086/650528

30. Yeligar SM, Chen MM, Kovacs EJ, Sisson JH, Burnham EL, Brown LA. Alcohol and lung injury and immunity. Alcohol. (2016) 55:51-9. doi: 10.1016/j.alcohol.2016.08.005

31. Kuznetsov VN, Shelygin KV, Grjibovski AM, Mariandyshev AO, Johansson $\mathrm{E}$, Bjune GA. Incidence of tuberculosis and associations with indicators of alcohol consumption in three regions of northwest Russia in 19752009: a time-series analysis. J Environ Public Health. (2013) 2013:1-5. doi: 10.1155/2013/693963

32. Al-Rifai RH, Pearson F, Critchley JA, Abu-Raddad LJ. Association between diabetes mellitus and active tuberculosis: a systematic review and metaanalysis. PLoS ONE. (2017) 12:e0187967. doi: 10.1371/journal.pone.0187967

33. Perez-Navarro LM, Restrepo BI, Fuentes-Dominguez FJ, Duggirala R, Morales-Romero J, López-Alvarenga JC, et al. The effect size of type 2 diabetes mellitus on tuberculosis drug resistance and adverse treatment outcomes. Tuberculosis. (2017) 103:83-91. doi: 10.1016/j.tube.2017. 01.006

34. Lan R, Yang C, Lan L, Ou J, Qiao K, Liu F, et al. Mycobacterium tuberculosis and non-tuberculous mycobacteria isolates from HIV-infected patients in Guangxi, China. Int J Tuberc Lung Dis. (2011) 15:1669-75. doi: $10.5588 /$ ijtld. 11.0036

Conflict of Interest Statement: The authors declare that the research was conducted in the absence of any commercial or financial relationships that could be construed as a potential conflict of interest.

Copyright (c) 2019 Chen, Peng, Xiong, Peng, Luo, Zou and Chen. This is an openaccess article distributed under the terms of the Creative Commons Attribution License (CC BY). The use, distribution or reproduction in other forums is permitted, provided the original author(s) and the copyright owner(s) are credited and that the original publication in this journal is cited, in accordance with accepted academic practice. No use, distribution or reproduction is permitted which does not comply with these terms. 